\title{
MUJER Y SOCIALISMO (1848-1939)
}

\section{Rosa Ma Capel Martínez}

La fecha de 1848 aparece relacionada en los libros de historia y cronologías al uso con los procesos revolucionarios conocidos como La primavera de los pueblos. Procesos que estallaron durante el mes de febrero en Francia y se extendieron con rapidez por diversos estados de la Europa central e Italia. Su inicio coincidió con la aparición en Londres del Manifiesto Comunista, obra encargada a Marx y Engels por la Liga Comunista alemana para contar con un programa teórico y práctico que dirigiera sus pasos. El destino superó con creces las expectativas y acabó convirtiéndola en el documento más extendido de la literatura socialista de todos los tiempos y en el punto de partida no sólo del socialismo científico sino también del movimiento obrero posterior.

Apenas cinco meses después, tuvo lugar otro acontecimiento bastante menos conocido, o reconocido, aunque tan importante como los anteriores toda vez que de él derivó el otro suceso revolucionario para la sociedad del momento y trascendental para el mundo actual. Se trata de la Woman's Rights Convention, celebrada en Seneca Falls (New York) el 19 y 20 de julio, con el objetivo de denunciar la situación de inferioridad en que vivía el sexo femenino y vindicar todos sus derechos. El acto lo convocaron dos abolicionistas, Elizabeth C. Stanton y Lucretia Mott, convencidas de la necesidad de una lucha específica por la igualdad de los sexos tras no ser admitidas a un congreso antiesclavista en Londres por el mero e inevitable hecho de ser mujeres. Los allí reunidos aprobaron la Declaration of Sentiments (Declaración de Sentimientos), llamada a ser el programa teórico y práctico del recién nacido feminismo. 


\section{Socialismo y feminismo: dos caminos hacia la igualdad}

La coincidencia temporal de estos eventos bien pudiera considerarse un mero fruto del azar, de no ser porque el paralelismo entre obrerismo y feminismo va más allá de lo cronológico. Ambos nacen de la Ilustración, cuyo enunciado del principio de igualdad natural de todos los seres humanos abrió brecha en las bases del ordenamiento estamental vigente y en la generalizada creencia acerca de la inferioridad natural femenina ${ }^{1}$. Las revoluciones americana y francesa de finales del siglo XVIII se hicieron para incorporar el ideal igualitario a la práctica política, al tiempo que la situación de excepcionalidad que representaron permitió creer que todos los cambios, incluso los más radicales, serían posibles. Las mujeres participaron activamente en ambos procesos ${ }^{2}$. Bien es verdad que la mayoría entendió esa presencia como extensión momentánea y circunstancial de sus obligaciones familiares al conjunto social. Pero también hubo una minoría que creyó vivir los albores de una era donde las relaciones entre los sexos dejarían de estar regidas por su sumisión. Recuérdense, a modo de ejemplo, las palabras de Abigail Adams a su esposo en 1776

«en el nuevo Código de Leyes, el cual supongo que les será necesario hacer, deseo que se acuerden de las Señoras, y que sean más generosos y favorables con ellas que sus ancestros. No pongan tan ilimitado poder en las manos de los Esposos. Recuerde que todos los Hombres serían tiranos si pudiesen. Si no se presta particular cuidado y atención a las Señoras estamos determinadas a fomentar una Rebelión, y no nos consideraremos sujetas por ningunas de las leyes en las cuales no hemos tenido voz o Representación»³.

Recuérdese, igualmente, la figura de Olympe de Gouges y su Declaración de Derechos de la Mujer y de la Ciudadana (1791). En ella transponía los términos de su homónima del «Hombre y el Ciudadano» a un sujeto específico: las mu-

1. Bolufer Peruga, Mónica, Mujeres e Ilustración. La construcción de la feminidad en la España del siglo XVIII, Valencia, 1998 y CAPEL MARTínEZ, Rosa Ma , «Mujer y espacio público a fines del siglo XVIII», en Antonio Morales Moya y Octavio Ruiz Manjón (eds.), 1802. España entre dos siglos. Tomo II. Sociedad y Cultura, Madrid, 2003, pp.139-162.

2. Entre la abundante bibliografía sobre este tema cabe citar las obras de: RENDALL, Jane, The origins of modern feminism: women in Britain, France and the United State, 17801860, London, 1994; BOHRER, Melissa L., Glory, passion and principle. The story of eight remarkable women at the core of the American Revolution, New York, 2003. BERKIN, Carol, Revolutionary mothers. Women in the struggle for America's Independence, New York, 2005. HESSE, Carla, The other Enlightenment. How French Women became modern, Princenton, 2001. DUHET, Paule Marie, Las mujeres y la revolución (1789-1794), Barcelona, 1974.

3. CAPEl Martínez, Rosa $M^{a}$, «Preludio de una emancipación. La emergencia de la mujer ciudadana», Cuadernos de Historia Moderna (Anejo VI, 2007: Cambio social y ficción literaria en la España de Moratín. Coordinado por Teresa Nava Rodríguez), pp. 155-179. 
jeres, finalizando con un alegato a las francesas para que se rebelaran contra el injusto trato recibido.

«Oh, mujeres! ¡Mujeres! ¿Cuándo dejaréis de estar ciegas? ¿Qué ventajas habéis obtenido de la Revolución? Un desprecio más marcado, un desdén más visible. Cualquiera sean los obstáculos que os opongan, podéis superarlos; os basta con desearlo» ${ }^{4}$.

No obstante estos precedentes, la sociedad burguesa del siglo XIX se mostró inconsecuente con los principios de igualdad y libertad sobre los que decía fundamentarse. Los derechos se reservaban a la minoría burguesa. "Ciudadana» no significaba otra cosa que «esposa de un ciudadano», educándosela para soportar la adversidad, más que para vencerla; para acatar un conjunto de roles, deberes y derechos distintos de los masculinos. Ahora bien, los mismos argumentos políticos liberales que justificaban la sociedad establecida señalaban lo que podían exigir a cuántos se encontraban al margen de ella, ya fuera por razones económicas, de género o de raza, e iban a hacerlo.

Otro punto de coincidencia entre feminismo y socialismo se halla en la denuncia de la discriminación que sufrían las mujeres y la reivindicación de sus derechos que asumieron. Ahora bien, en este caso, la coincidencia va unida a la divergencia que engendran los presupuestos de partida desde los que ambos movimientos abordaron el análisis de los problemas y propusieron soluciones. Para las y los feministas todas las mujeres, con independencia de la clase social, vivían la misma situación de esclavitud y estaban excluidas de los derechos naturales que disfrutaban los hombres. Dado que todos los seres eran «creados iguales», que habían sido «dotados por el Creador de ciertos derechos inalienables» y que los gobiernos se establecían para «asegurar estos derechos», había llegado el momento de que las mujeres se alzaran para exigir el reconocimiento de la igualdad de los sexos, establecida por Dios para «el bien de la raza humana $»^{5}$. En la práctica, esto se traducía en la demanda de recibir una educación y desempeñar todos los oficios para los que se capaciten, de gozar de personalidad jurídica propia y de poder para administrar sus bienes, de tener reconocido el ejercicio del voto cuando se cumpliesen las condiciones generales establecidas. Las anglosajonas convirtieron pronto esta

4. Condorcer, De Gouges, De LAmbert y otros, La polémica de los sexos en el siglo XVIII, edición de Alicia H. Puleo, Barcelona, 1993, pp. 155-160. Un análisis más detenido del contenido del texto al que nos referimos se encuentra en CAPEL MARTínez, Rosa $\mathrm{M}^{a}$, «Preludio de una emancipación...».

5. Declaration of Sentiments. Seneca Falls, 1848. Cfra.: CAPEL MartíneZ, Rosa $\mathrm{M}^{\mathrm{a}}$, «Jalones de una emancipación: sufragismo y feminismo, 1840-1940», en VALCÁRCEL, Amelia, RENAU, $\mathrm{M}^{\mathrm{a}}$ Dolores y ROMERO, Rosalía (eds.), Los desafíos del feminismo ante el siglo XXI, Sevilla, 2000, pp. 79-103. 
última reivindicación en el eje central de su lucha, considerándola la clave para todas las restantes. De ahí que en su caso, y en otros similares, esta primera fase del movimiento feminista, que termina tras la I Guerra Mundial, reciba la denominación de «Sufragismo» ${ }^{6}$.

El socialismo, por su parte, entendía la denominada «cuestión femenina» como un aspecto de la más amplia e importante «cuestión social», pues ni las mujeres constituían un grupo diferenciado ni la situación de sumisión en que vivían, las discriminaciones que soportaban, tenían raíces específicas. Como el resto de las opresiones derivaban de la existencia de propiedad privada y de su exclusión de la esfera productiva, lo que las hacía dependientes de los hombres. A esa supeditación, eso sí, había que sumar otra específica derivada del modelo de familia vigente, donde los esposos constituían «la burguesía» y las esposas «el proletariado». El burgués, dirían Marx y Engels, «no ve en su mujer más que un simple instrumento de producción ${ }^{7}$, haciéndole cumplir, añadiría más tarde Pablo Iglesias, el papel de esclava, objeto de placer o de adorno ${ }^{8}$. El socialismo pretendía acabar con todo esto, pero no iniciando una lucha como la de las sufragistas, de la que sólo cabía esperar reformas que podían dar libertad e independencia a unas pocas, sin alcanzar la dignificación y la libertad de todas porque dejaba intactas las verdaderas causas que las impedían. La emancipación de la mujer había de ir, iba indisolublemente unida a la de la clase obrera, pues eran dos aspectos de una misma lucha: la que llevaba a la desaparición del sistema de producción capitalista y del «vetusto régimen burgués» que de él deriva, "amparador de todas las injusticias, causa de todas las infamias, representante de todas las tiranías, generador de todas las esclavitudes $»^{9}$. Si el socialismo era emancipación y justicia, y el feminismo era justicia y emancipación, ambos debían caminar al unísono. La instauración del socialismo aportaría a las mujeres la independencia económica que precisaban para ser libres y unas relaciones de compañerismo en lugar de sumisión. Por tanto, era a la revolución social a la que debían unirse; era la que debían anteponer a cualquier otra. Para ello, nada mejor que integrarse en las sociedades obreras ya constituidas, donde laborarían junto a los hombres como compañeras por unos mismos objetivos.

6. Entre la abundante bibliografía sobre la historia del movimiento feminista en esta primera etapa una de las más completas por el espacio geográfico abarcado es la de OFFEN, Karen, European Feminisms. 1700-1950. A political History, Stanford, 2000.

7. MARX, Karl y ENGELS, Frederic, Manifiesto Comunista, Londres, 1848. Capítulo II.

8. Pablo Iglesias, «La emancipación de la mujer», El Socialista, Madrid, 15-I-1897.

9. Feminismo. Escrito anónimo ológrafo. Agrupación Socialista Madrileña. Archivo y Biblioteca de la Fundación Pablo Iglesias. 
Estos planteamientos teóricos se llevaron a la práctica, sin embargo, de manera bien diferente, pues los problemas femeninos ocuparon un lugar secundario en la estrategia de los partidos socialistas y de los sindicatos de clase. Es más, deudores de un determinado tiempo, de una determinada mentalidad, líderes y afiliados no siempre apoyaron a las compañeras en sus reivindicaciones -igualdad salarial, mejores puestos de trabajo, derechos civiles, etc.-. En los primeros tiempos, incluso, fueron muchas las voces alzadas en favor de suprimir el trabajo femenino por la competencia que hacía al masculino. Algo que Pablo Iglesias consideraba una pérdida de tiempo, en primer lugar «porque no han de conseguirlo»; en segundo lugar, porque resultaba poco recomendable en términos estratégicos, toda vez que eliminaba «del ejército que en el campo económico pelea contra el capital un buen número de combatientes». Sería mucho más útil para evitar la nefasta concurrencia «atraer a las obreras a las filas societarias y reclamar para ellas el mismo salario que se da al trabajador» ${ }^{10}$.

El paso de los años fue haciendo más difícil seguir negando que existían intereses comunes entre las mujeres, que las relaciones de género tenían dinámicas independientes de las de clase y que, con relativa frecuencia, trabajadores y trabajadoras entraban en contradicción. Hechos todos que, además, colocaban a muchas líderes socialistas en situaciones personales incómodas. Si a ello unimos el auge de un movimiento feminista que comenzaba a ejercer cierto atractivo entre las mujeres del proletariado, tendremos dibujado el marco que explica el que en los dos últimos decenios del siglo XIX se alzaran voces matizando los postulados teóricos iniciales. Augusto Bebel abrió el camino al publicar La mujer ante el socialismo (1879), obra que Clara Zetkin consideró un acontecimiento más que un libro, pues por vez primera se resaltaban las conexiones entre «cuestión femenina» y desarrollo histórico. El público pareció darle la razón, pues la obra conoció hasta cincuenta ediciones sólo en Alemania antes de la muerte de su autor en 1913. Cuando finalizaba la centuria, la propia Zetkin insistía en la existencia de una «cuestión femenina» ante el Congreso del Partido Social-Demócrata Alemán $(1896)^{11}$, si bien la clase social introducía diferencias en las formas que revestía. Apoyaba, asimismo, la reclamación de derechos del feminismo burgués, incluida la igualdad política, toda vez que su lucha no estaba movida sólo por razones económicas

10. Pablo Iglesias, «La explotación de la mujer y del niño», El Socialista, Madrid, 1-VI-1888.

11. ZETKIN, Clara, "Only in conjunction with the proletarian woman will Socialism be victorious». Intervención en el Congreso del Partido Social Demócrata de Alemania. Gotha, 16 de octubre de 1896. Dentro de la obra ZETKIN, Clara, Selected Writings, editada por Philip Foner, New York, 1984. 
sino también por otras espirituales y morales más profundas. Ahora bien, para la líder germana estas conquistas no podían constituir fines en sí mismas, sino «medios para entrar en la batalla contra la sociedad burguesa junto al proletario equipadas con las mismas armas». Años más tarde, la rusa Alejandra Kollontai añadiría otros elementos a la explicación económica de la subordinación femenina. Desde su punto de vista, resultaban decisivas en la misma medida: las relaciones de poder dentro de la familia, la moralidad y la sexualidad. De ahí que entendiera necesaria una revolución cultural paralela a la social para transformar definitivamente las relaciones interpersonales.

Es, asimismo, en los años finales del siglo XIX e inicios del siglo XX cuando aparecen los primeros grupos y asociaciones dirigidas exclusivamente a las mujeres dentro de las filas socialistas. Se esperaba que la medida facilitaría la consideración de los problemas femeninos y una mayor integración de afiliadas. «La incorporación de grandes masas de mujeres proletarias a la lucha del proletariado por su liberación», escribía Clara Zetkin, «es uno de los prerrequisitos para la victoria de la idea Socialista y la construcción de la sociedad Socialista». Algo venía haciendo ella en este sentido a través de las páginas de Gleichleit, publicación periódica que editó de 1892 a 1917. Pero, según confiesa, la revista se dirigía a una minoría de mujeres conocedoras del socialismo antes que a la mayoría de las integrantes de la clase obrera. A éstas había que atraerlas por medio de la propaganda bien hecha y la facilidad para que se asociaran. La idea tuvo eco casi inmediato en varios países, entre los que cabe contar a España. Fruto de ese eco puede considerarse el que la líder alemana reuniera la I Conferencia Internacional de Mujeres Socialistas, dentro del VII Congreso de la Internacional Socialista que tenía lugar en Stuttgart en 1907. Las 58 delegadas de todo el mundo asistentes constituyeron la Internacional Socialista de Mujeres bajo la presidencia de la propia Clara. Los esfuerzos se centraron en defender los derechos políticos femeninos y en abogar por la paz, temas de la siguiente reunión celebrada en 1910 y de la que salieron dos importantes resoluciones: un manifiesto pacifista y la institucionalización del Día Internacional de la Mujer para visibilizar su lucha emancipadora. Los dos primeros años la fiesta se celebró el mismo día en que se conmemoraban los sucesos de la Comuna de París, para finalmente quedar fijada en el actual 8 de marzo ${ }^{12}$.

12. Ramos Palomo, $M^{a}$ Dolores, «Una conmemoración propia, un ritual feminista. Orígenes y antecedentes del 8 de Marzo», en CAPEl MarTínez, Rosa $\mathrm{M}^{a}$ (edit.), Cien años trabajando por la igualdad (en prensa). 


\section{El socialismo y los grupos femeninos en España. 1879-1936}

El tema de la emancipación de la mujer es abordado por los socialistas en España siguiendo los términos y con la secuencia que lo hacen los compañeros de otros países ${ }^{13}$, si bien los esfuerzos por captar a la población femenina se demoran hasta iniciado el siglo XX, cuando tiene lugar la incorporación creciente de las españolas a la esfera productiva y a la enseñanza, el primer feminismo burgués se consolida, y el fuerte peso de la Iglesia dentro de la sociedad añade una potente rémora ante cualquier cambio.

Dentro de nuestro socialismo coexistieron tres sensibilidades acerca de la colaboración femenina y de las reivindicaciones que debían exigirse para este sexo. De un lado, la de los militantes que entienden la igualdad entre hombres y mujeres como un ideal político-jurídico, en modo alguno, social. Conforme a los más puros principios patriarcales, mantienen que la verdadera dicha de las mujeres radica en el amor, el marido y los hijos, mientras atacan al feminismo por antinatural ${ }^{14}$. De otro lado, estaban quienes reducían los cambios a convencer al obrero de que tenía dos responsabilidades. Una, según rezaba el noveno mandamiento del «Decálogo Socialista» de 1908, «respetar y honrar a la mujer como compañera e igual que es del hombre, luchando desde ahora para que no sea más ni del prójimo ni de nadie, sino sólo de sí misma». Dos, inculcar los ideales socialistas en sus madres, esposas, primas o novias para que supieran educar el hogar y preparar a los hijos, para traerlas a las reuniones arrancándolas de las garras del cura y del capital ${ }^{15}$. La insistencia en estos dos deberes de los militantes por parte de los líderes y de la Comisión Ejecutiva del $\mathrm{PSOE}^{16}$ a lo largo de los años nos habla tanto de la relevancia que se les otorgaba como de su incumplimiento.

La tercera postura la encarnan quienes entienden que socialismo y feminismo son movimientos diferentes, porque las obreras sufren mayor explotación económica que las burguesas, pero articulables, porque ambos buscan la emancipación de la mujer y porque «hay problemas que no son de 'clase' ni de 'casta'; sino de sexo»; discriminaciones legales, sociales, familiares que han de ser abordadas específicamente para ponerles fin. Esta perspectiva va a ser mantenida esencialmente por mujeres (Amparo Martí, María de Lluria, Isabel

13. Para un análisis más detenido y extenso del tema véase: CAPEL MARTíneZ, Rosa $M^{a}$, Socialismo e igualdad de género. Un camino común, Madrid, 2007.

14. El Socialista, 1910-1911.

15. Isidoro Acevedo, «La mujer y el socialismo», El Socialista, Madrid, 1-V-1911. En el mismo sentido se expresaba Victoriana Herrero en El Socialista de 2-XI-1928.

16. A la Comisión Ejecutiva del PSOE se le debe la circular titulada La mujer y el Partido Socialista, aparecida en El Socialista el 11-VI-1929. 
Muñoz Caravaca...), adquiriendo entidad en los años veinte, cuando el tema del «feminismo socialista» aparece en la prensa, se debate en los Congresos y María Cambrils ${ }^{17}$ publica un libro con ese título. Para quienes se incluyen en esta corriente, las mujeres, además de aportar su esfuerzo a la evolución de la Humanidad y la lucha proletaria, deben concienciarse de sus derechos y deberes. Su liberación no es sólo terminar con la explotación laboral o el control de la Iglesia que sufren. Liberarlas significa, también, poner fin al «rebajamiento personal» que representa la dependencia civil en que la colocan los Códigos y el sometimiento que experimenta dentro de la familia burguesa. No hay más fundamento para decir que la mujer ha de ser esposa y madre que para decir que el hombre ha de ser esposo y padre. Es más, educar a la mujer para esposa sin asegurarle el matrimonio, y para madre sin asegurarle la maternidad no es sino un enorme error porque ambos son contingentes. Lo único cierto es que ha de vivir, que viene «al mundo para cumplir los mismo fines que el hombre; (...) y debe, consiguientemente, tener los mismos derechos ${ }^{18}$. Esos derechos componían una larga lista: igualdad laboral, salarial, educativa y civil; sufragio, considerado por Muñoz Caravaca ${ }^{19}$ lo primero y principal; divorcio, una medida reparadora de justicia, y la refundación y moralización del matrimonio sobre la base del desinterés económico, la tolerancia mutua y la unión libre basada en el mutuo sentimiento. Todas estas conquistas sólo serán posibles con la profunda transformación de la sociedad que el socialismo encierra. Para lograrlo se propone una doble vía de acción: la del PSOE, considerando la emancipación de las mujeres como una de sus tareas políticas más importantes, y la de aquéllas, acercándose al movimiento obrero, sacudiéndose «ese estado de catalepsia espiritual en que la sumieron los prejuicios masculinos y su incomprensible resignación $»^{20}$, y aspirando a ser compañeras del hombre, no meras colaboradoras.

La llamada de las feministas socialistas de los años veinte a la integración de las españolas en el partido o en los sindicatos era más estructurada, pero no era nueva. Sin embargo, todas tuvieron un eco limitado. Para 1910, sólo había 36 mujeres entre los 2.900 militantes de la Agrupación Socialista Madrileña. En 1927, la Federación Nacional de Juventudes Socialistas de España admitía contar con 24 afiliadas sobre un total de 1.182 militantes $^{21}$. Es más, de 1929 a

17. CAmbrils, María, Feminismo socialista, Valencia, 1925, p. 19.

18. A. Aguilar, «Feminismo», Vida Socialista, 25-X-1910, p. 7.

19. Isabel Muñoz Caravaca, «El voto femenino», Acción Socialista, Madrid, 27-VI-1914.

20. CAMBRILS, María: Feminismo socialista..., p. 19.

21. Federación de las Juventudes Socialistas de España, II Congreso Ordinario: orden del día y memoria. Madrid, 11 a 17 de Mayo de 1927, Madrid, 1927. 
1936, cuando la concienciación femenina ganó tantos enteros, sólo 358 españolas solicitaron ingresar por 5.376 españoles $^{22}$. Y es que los obstáculos para la militancia femenina eran significativos: analfabetismo, falta de tiempo para asistir a las reuniones dada la prioridad de los trabajos domésticos, dificultades para pagar las cuotas, pese a ser a veces la mitad de las masculinas, desinterés de los compañeros, cuando no rechazo, etc. Para vencer estas y otras barreras, el PSOE creó los Grupos Femeninos a inicios del siglo XX, siguiendo el ejemplo exterior. La iniciativa parte de las Juventudes Socialistas de Bilbao, justo un año después de que Tomás Meabe las fundara. En su seno nace el primer Grupo Femenino Socialista el 14 de julio de 1904, tras una conferencia de la obrera guarnicionera y ugetista Virginia González sobre ideales societarios y reivindicaciones femeninas ${ }^{23}$. Dos años después, el 25 de marzo de 1906, nacía el Grupo Femenino Socialista de Madrid. Unido inicialmente, también, a las Juventudes, en 1908 se integró en la estructuras del PSOE, donde permanecerá hasta 1927, cuando se disolvió la Agrupación a propuesta del Comité Ejecutivo del partido, en el que se integraron las militantes ${ }^{24}$.

Las iniciativas vasca y madrileña generaron mimetismo en otras partes de España, si bien resulta difícil de conocer su dimensión porque las informaciones parciales existentes apenas permiten ir más allá de una aproximación al proceso. Sabemos que tanto las Juventudes como el partido se sintieron comprometidos con la constitución de grupos femeninos a todo lo largo del período ${ }^{25}$. Sabemos que el movimiento asociacionista presenta un ritmo alternativo de acuerdo con los acontecimientos generales del país, dándose la mayor actividad fundacional en los años diez -período de protesta social por la guerra de Marruecos, la crisis económica, el conflicto mundial, etc.- y en los treinta -II República y Guerra Civil-. El Almanaque de El Socialista de 1914 tenía localizados Grupos Femeninos en Bilbao, Madrid, Barcelona -creado por Amparo Martí en 1911-, Erandio (Vizcaya, 1914), Capdepera (Bilbao), Eibar (Guipúzcoa), Gallarta (Vizcaya), Mieres (Asturias), Sevilla y

22. BIZCARRONDO, Marta, «Los orígenes del feminismo socialista en España», en VV.AA., La mujer en la historia de España (Siglos XVI-XX), Madrid, 1984, pp. 137-158.

23. La Lucha de Clases, Bilbao, 16-VII-1904. Archivo y Biblioteca de la Fundación Pablo Iglesias.

24. Agrupación Socialista Madrileña, Actas de las Asambleas Generales. 26 de Febrero de 1927-21 de Diciembre de 1932. Actas del 26 de Febrero y del 19 de Agosto de 1927; y Actas del Comité. 26 de Febrero de 1927-21 de Diciembre de 1932. Actas del 3 y 24 de Febrero, 31 de Marzo, 5, 12 y 19 de Mayo, y 14 de Julio de 1927. Archivo y Biblioteca de la Fundación Pablo Iglesias.

25. Convocatoria y orden del día para el X Congreso y memoria reglamentaria de la Comisión Nacional, Madrid, 1915; Resoluciones del IV Congreso Nacional. Madrid, febrero de 1932, Madrid, 1932. Archivo y Biblioteca de la Fundación Pablo Iglesias. 
Reus (Tarragona). Para 1916 se les han sumado los de Elche, Valencia y Yecla (Murcia), y en julio de 1920, los de Puertollano (Ciudad Real) -con 100 afiliadas- y Castellón. Por último, el período republicano ve crearse las agrupaciones femeninas de Navas de San Juan (Jaén, 1931), Camuñas (Toledo, 1932), Puebla de Cazalla (Sevilla, 1934), Puebla de Alcocer (Badajoz, 1934)26, Helechal (Badajoz, 1936), El Bonillo (Albacete, 1936), Cazorla (Jaén, 1936) y el Círculo Femenino de Bilbao (1935). En plena Guerra Civil hay noticias de un nuevo Grupo Femenino Socialista en Madrid, que se reúne con los Círculos Sociales de diferentes distritos de la capital en 1937; del de Urrea de Gaén (Teruel) y de la instalación en Barcelona del Círculo Femenino Socialista de Vizcaya (1938), así como de la constitución de un Secretariado Femenino, al que me referiré más adelante ${ }^{27}$.

El funcionamiento interno de estos grupos estaba fijado en los Estatutos correspondientes, cuya lectura deja ver el carácter de modelo que tuvo el de la Agrupación Femenina Socialista de Madrid, aprobado el $1910^{28}$. Éste, a su vez, era una adaptación de la Organización Local de la Agrupación Socialista Madrileña, de la que toma estructura y contenidos, faltando sólo los apartados referidos al Comité Electoral y la Caja de Solidaridad.

Según estos textos, el objetivo de los grupos femeninos era «educar a la mujer para el ejercicio de sus derechos y la práctica de sus deberes sociales con arreglo a los principios de la doctrina socialista»; fomentar las sociedades de mujeres, y cooperar para conseguir leyes a favor del trabajo femenino e infantil. Resulta interesante la variante que introduce el Estatuto de la Asociación Socialista Femenina de Helechal (Badajoz), que sitúa como primer motivo «intervenir en todas las luchas políticas de acuerdo con el programa del PSOE, aceptándose su reglamento siempre que no se salga del concepto marxista y revolucionario». En suma, los grupos femeninos buscaban acercar el socialismo a las mujeres y las mujeres al socialismo, aunque no todas ni todos los militantes dieron idéntica dimensión a este acercamiento. María Cambrils, por ejemplo, los consideraba organismos feministas «francamente políticos», nacidos para la defensa colectiva de las libertades civiles de este sexo, junto con el problema económico. Sus puertas, por tanto, habían de estar abiertas a

26. La fecha es orientativa, pues se ha deducido de la petición formulada en 1937 para que se les rebaje la deuda por cuotas impagadas. Cfra.: Archivo de la Comisión Ejecutiva del PSOE. 1928-1940. Censo de Agrupaciones. Sociedad Femenina. Puebla de Alcocer. Archivo y Biblioteca de la Fundación Pablo Iglesias.

27. Capel Martínez, Rosa $\mathrm{M}^{\mathrm{a}}$, Socialismo e igualdad..., pp. 40-42.

28. Organización local de la Agrupación Femenina Socialista. Madrid. Madrid, PSOE, 1925. Archivo y Biblioteca de la Fundación Pablo Iglesias. 
cuantas reivindicaran esos derechos y a ninguna se le pediría que renunciara a sus creencias religiosas para ingresar ${ }^{29}$. Interpretación menos positiva es la de Manuel Vigil, para quien debían ser «escuela de madres, escuela de esposas» para los militantes.

Para ingresar en los Grupos se exigía a la aspirante solicitarlo por escrito, mostrar conformidad con el programa del PSOE, y pertenecer a la Sociedad de resistencia de su oficio, salvo causas justificadas. En algunos casos se añadía el aval de dos militantes, y el Grupo de Helechal pedía estar «en pleno uso de sus derechos político y sociales». En todos los casos «se considera necesario que las afiliadas», lo mismo que los afiliados, «observen una conducta honrada», norma cuyo incumplimiento podía suponer la expulsión, lo mismo que faltar a la solidaridad obrera, calumniar a una compañera, no cumplir los acuerdos y adeudar de tres a seis mensualidades sin justificación. Los Grupos se disolverían de no alcanzar una cifra mínima de afiladas -5 ó 10-, pasando los fondos al PSOE. Entre los deberes de las inscritas figuraban: cumplir los objetivos del Grupo, leer y propagar la prensa obrera, concurrir a los actos programados, y abonar una cuota cuya cuantía oscilaba entre 30 y 15 cénts. mensuales. El apartado de derechos incluía gozar de voz y voto en las Asambleas, recibir el carnet de la Organización General del PSOE, fiscalizar la Administración, ser elegida para cargos, y leer los libros de la Biblioteca, aspecto éste que habla de la preocupación que el socialismo mostró siempre por la formación cultural de la clase obrera como instrumento de su emancipación. El grupo «El Despertar Femenino» de Yecla ofrecía, excepcionalmente, preferencia a la hora de trabajar.

La dirección de los Grupos Femeninos recaía en el Comité Ejecutivo, compuesto por: Presidenta, Vicepresidenta, dos Secretarias, Tesorera, Contadora y 3 Vocales, cargos para los que son elegibles todas las afiliadas al corriente de sus cuotas, teniendo la obligación de aceptarlos. Los Estatutos de Yecla y Helechal añaden el requisito de saber leer y escribir ${ }^{30}$. El Comité había de renovarse cada mes de enero, correspondiéndole tareas de gestión y representación, a las que en Helechal se añade la elección y fiscalización de las concejales que la representan. Las Juntas Ordinarias semanales del Comité se reunirían cada semana y la Asamblea General Ordinaria cada cuatro meses. La Agrupación Femenina Socialista de Madrid añadía una Comisión Asesora de Cuentas y una Mesa de Discusión a sus órganos directivos, así como un

29. CAMBRils, María, Feminismo socialista..., p. 57.

30. El requisito pudiera venir determinado por el hecho de ser zonas de alto analfabetismo. Cfr.: CAPEl Martínez, Rosa $\mathrm{M}^{a}$, El trabajo y la educación de la mujer en España (19001930), $2^{a}$ edic., Madrid, 1986. 
Asesor y un Vice-asesor con voz pero sin voto, representantes de las Juventudes, primero, y de la Agrupación Socialista Madrileña, después.

La escasez de informaciones sobre los Grupos Femeninos, ya aludida, se incrementa a la hora de conocer cuántas afiliadas llegaron a tener y cómo evolucionaron. Sólo constan referencias directas a la cifra mínima exigida para constituirlos y mantenerlos -5 ó 10 socias-, y a las que había cuando algunos se formaron -Bilbao, 150 militantes; Puertollano, un centenar-. Estas cifras parecen algo elevadas teniendo en cuenta la situación de las españolas y los datos que aporta el Libro de Registro de Asociadas del Grupo Femenino Socialista de Madrid, único conservado completo (1906-1927) y que paso a analizar.

Según las anotaciones, había seis afiliadas en el momento de fundarse: María Méndez, planchadora, Purificación Hernández, sastra de 49 años, Isabel Vega, guarnecedora, Juana Taboada, «sus labores» y 30 años, María García, profesora en partos de 28 años, y María Rueda, de la que no consta ninguna otra información. Sin embargo, el acta de constitución incluye los nombres de las quince integrantes del Comité Directivo y de las tres de la Comisión de Revisión de Cuentas. Este desajuste entre Registro y Actas puede atribuirse bien a que la falta de afiliadas obligara a recurrir a las militantes de algunas sociedades obreras para cubrir los cargos adecuadamente aunque no se afiliaran de inmediato al Grupo, o bien a una inexactitud documental. En cualquier caso, el aumento de afiliaciones fue lento en los primeros tiempos. Para finales de 1906 había sólo 18 inscritas, que son 65 dos años después. El recrudecimiento de la protesta social a finales de esa década hace crecer las afiliadas, trayectoria que se consolida por efecto de la posterior alianza electoral de socialistas y republicanos, que atrajo a mujeres procedentes de las «Damas Rojas», por la victoria de Pablo Iglesias en los comicios generales, y por la campaña de 1911 en favor de prohibir el trabajo nocturno femenino. A fines de este año se contabilizaban 159 afiliadas $^{31}$, que subieron a 164 en 1916. A partir de ahí comienza un permanente descenso hasta las 70 militantes en el momento de su disolución (1927). Según el estudio de Moral Vargas ${ }^{32}$, la geografía del domicilio de las afiliadas coincide con los distritos más humildes de la ciudad: Universidad, Hospital y Chamberí, por este orden.

31. Libro de Registro de Asociadas al Grupo Femenino Socialista de Madrid. 1906-27. Archivo General de la Guerra Civil y Archivo y Biblioteca de la Fundación Pablo Iglesias.

32. Moral VArGaS, Marta del, «El Grupo Femenino Socialista de Madrid (1906-1914): pioneras en la acción colectiva femenina», Cuadernos de Historia Contemporánea, vol. 27 (2005), pp. 247-269. 
Pese a que las normas establecían la pertenencia obligatoria a una sociedad de oficio antes de ingresar en la Agrupación, Nash señala que la mayor parte de las militantes madrileñas -394 de un total de 527-aparecen sin profesión o se señala «sus labores»; de las restantes, el bloque más numeroso trabaja en la confección -83-, habiendo representantes de la enseñanza, sanidad y servicio doméstico, entre otros sectores. En cuanto al tiempo de militancia, 166 llegaron a tener más de diez años, y un número similar -156- permaneció entre cinco y diez. Las que no cumplen el año de afiliadas fueron 98. La autora del estudio estima estos datos consecuencia de un fuerte grado de conciencia y compromiso con las ideas socialistas ${ }^{33}$.

Lo normal es que la afiliada permaneciera dentro del grupo hasta su baja definitiva, sin embargo hay casos en que sale y vuelve a ingresar pasado un tiempo más o menos largo. Tal sucede con Carmen Jordán y Carmen de Burgos, quienes solicitaron la baja voluntaria por motivos parecidos. La Jordán al ser recriminada por el Comité tras haber participado sin autorización en un mitin anticlerical en el verano de 1910. Después de retirar las palabras ofensivas contenidas en su carta de renuncia, se le readmite a los pocos días ${ }^{34}$. Burgos, por su parte, se marchó en 1912 cuando otras dos compañeras le atribuyen haber hablado de forma poco favorable para los socialistas en un acto en el Círculo Radical. El tema ocupó tres reuniones del Comité a lo largo de dos meses. Finalmente reingresó en 1917, con la satisfacción de todas menos las denunciantes. Tampoco en esta ocasión superará los dos años de permanencia, pues en diciembre de 1919 se vuelve a dar de baja al exigirle los compañeros del Arte de Imprimir cumplir los estatutos y afiliarse a la sociedad para seguir en la Agrupación. Esta salida fue definitiva, aunque Colombine ${ }^{35}$ seguiría colaborando con la causa socialista, como lo hacían otras muchas mujeres que sin llegar nunca a inscribirse asistían a todos los actos y mítines de la Agrupación ${ }^{36}$.

33. NASH, Mary, Mujer y movimiento obrero en España. 1931-1939, Barcelona, 1981, p. 144.

34. Reunión de la Junta General de 28 de agosto de 1910. Cfr. Libro de Actas de las Juntas Generales. Marzo, 1906 - febrero, 1915. Archivo y Biblioteca de la Fundación Pablo Iglesias.

35. Una completísima biografía de Carmen de Burgos es la realizada por NÚÑEZ REY, Concepción, Carmen de Burgos, Colombine, en la Edad de Plata de la literatura española, Sevilla, 2005.

36. RALLE, Michel, «Les socialistes madrilènes au quotidien. I (des origines de l'Agrupación à 1910)», Mélanges de la Casa de Velázquez, Tomo 17 (1981), pp. 343 y ss. 


\section{Mujeres en acción}

La vida de los Grupos Femeninos Socialistas estuvo fuertemente vinculada a la del PSOE y los sindicatos, con los que compartían objetivos e intereses. Ahora bien, sería erróneo creer que se limitaron a seguir instrucciones de las direcciones superiores. Los Grupos fijaron también su propio programa, manifestaron sus opiniones, aún si no coincidían con la línea mayoritaria, y pusieron en marcha actividades acordes con las preocupaciones prioritarias en cada momento. El carácter de éstas últimas fue diverso: sindical, solidario, educativo-cultural, político, ideológico, propagandístico. Todo, pese a la penuria económica en que se movieron, de la que son buena prueba las periódicas suscripciones hasta para comprar útiles para las Secretarías y las solicitudes de exención de cuotas.

La Agrupación Femenina de Madrid guardó estrecha relación con los sindicatos obreros, compartiendo afiliadas y locales en la sede del PSOE con algunos femeninos -Lavanderas y Planchadoras, Sastras, Guarnecedoras,... Siempre apoyó las reivindicaciones proletarias, las huelgas convocadas y la fundación de nuevas sociedades, como el sindicato de Modistas en 1911 $11^{37}$. La solidaridad, asimismo, late tras las suscripciones y rifas promovidas para recoger fondos a favor de los compañeros y compañeras que los necesitaban -trabajadores en huelga, enfermos, presos, etc.-. Incluso se remitieron 5 pts. en 1907 para la Revolución Rusa y otras tantas para ayudar con los gastos del compañero Delegado al Congreso de la Internacional Socialista. Algunas militantes antepusieron estos compromisos a la recaudación para una bandera de la Agrupación cuando ésta se propuso.

La importancia dada a la educación y el elevado analfabetismo femenino otorgaron gran relevancia a las iniciativas para mejorar el nivel cultural de las integrantes de la clase obrera. Señalado queda lo que los Estatutos establecían al respecto -biblioteca, lectura de la prensa-, a lo que se suma el establecimiento de clases de cultura femenina y de higiene y economía doméstica; el desarrollo de diversos talleres, y la programación de conferencias. Éstas debieron tener bastante éxito, pues en 1911 se solicitó para celebrarlas el salón grande de la Casa del Pueblo. Se escogían temas de actualidad -voto, feminismo y mujer obrera, feminismo socialista, educación de la mujer, atención a las madres solteras, etc.- y figuras señeras para desarrollarlos Margarita Nelken, María Lejárraga, Clara Campoamor, Consuelo Álvarez y Cordero, María Cambrils, Valentina Generest de Nigro, Torralba Beci, Carmen de Burgos, la Dra. Soriano,...

37. Moral Vargas, Marta del, «El Grupo Femenino Socialista de Madrid..., pp. 257-258. 
La acción política y de propaganda de la Agrupación Femenina Socialista madrileña ocupó gran parte del tiempo de sus dirigentes e integrantes. Junto a la frecuente participación en actividades del Partido, de las Juventudes y de las sociedades obreras, estaban los mítines, veladas y reuniones organizados para atraer afiliadas, mostrar su repulsa por lo que acontecía en España o defender las reivindicaciones femeninas, en general, y las laborales, en particular. La asistencia a estos actos dependió de muchas variables, si bien debieron estar bastantes concurridos según cabe inferir de los testimonios gráficos y escritos aparecidos en la prensa. Para apoyarlos está el testimonio de Carmen Jordán, quien en 1910 elevó una protesta después de que muchas mujeres no pudieran acceder a un mitin programado en la Casa del Pueblo para ellas por haber ocupado su lugar en el salón otros compañeros. En los difíciles momentos vividos por la sociedad española durante la segunda década del siglo $\mathrm{XX}$, mítines y movilizaciones expresaban preferentemente la repulsa hacia el conflicto marroquí y contra la redención en metálico del servicio militar, que tanto perjudicaba a sus hijos. En 1917 se añadió la petición de amnistía para los detenidos durante la huelga general de ese verano. La acción de las mujeres en estas ocasiones fue tan decidida que alguna prensa no dudó en compararlas con las sufragistas inglesas. Es posible que muchas de las asistentes acudieran más en calidad de hijas, esposas, madres o hermanas de quienes se sentían oprimidos, que por sentirse protagonistas de una lucha propia. Las llamadas que se les dirigen, además, inciden más en aquel sentido que en éste. Sin embargo, el que estuvieran allí ya era un paso adelante.

Durante los años veinte, las movilizaciones se redujeron en número hasta desaparecer con la Dictadura, mientras la temática de los mítines se tornó más feminista. Así, el 3 de mayo de 1926 se celebró uno para pedir que se legislara sobre la investigación de la paternidad. Intervinieron: Julia Vega y Claudina García, por la Agrupación Femenina, Isabel Oyarzábal, escritora, Concepción Alexandre, médico, Clara Campoamor, abogada, y Carmen de Burgos, quien envió unas cuartillas para que se leyeran. Abordando el tema desde distintos puntos de vista, todas coincidieron en señalar la necesidad de una ley para investigar la paternidad y en denunciar la injusticia que se cometía con los hijos ilegítimos y las madres solteras, atacadas por la misma sociedad que nada decía del padre ${ }^{38}$. Con posterioridad a este acto se celebraron otros pidiendo abolir la prostitución, contra el $\mathrm{Art}^{\circ} 438$ del Código Penal, referido al adulterio, y un homenaje a Clara Campoamor por rechazar el nombramiento para la Junta del Ateneo que le había hecho Primo de Rivera.

38. El Socialista, 3-V-1926. 
Mención aparte merecen las actividades realizadas con motivo de las convocatorias electorales, especialmente a partir de que Pablo Iglesias obtuviera el escaño de diputado en 1910. Pese a no estar reconocido el sufragio femenino, los socialistas pidieron siempre a las integrantes de las clases trabajadoras que velaran por que sus maridos votasen a los candidatos del Partido y que no aceptasen propuesta alguna de cambiar su voto por una limosna. Las afiliadas a la Agrupación Femenina, además, dirigían llamamientos a todas las españolas durante las campañas; convocaban mítines con mayoría de oradoras; distribuían propaganda por distintas zonas y a las puertas de los colegios electorales, donde se les encargaba vigilar que la derecha no comprara los votos «de quienes de natural votaban a la izquierda» ${ }^{39}$. En marzo de 1914, un grupo pidió al presidente de una mesa asistir al escrutinio pese a no ser electoras; aquel aceptó argumentando que era un modo de prepararlas para el día cercano en que tendrían ese derecho ${ }^{40}$.

Resonancias políticas tienen, igualmente, los intensos debates vividos dentro de la Agrupación Femenina Socialista madrileña durante la preparación de propuestas para los Congresos del PSOE y de las Juventudes Socialistas o sobre temas tan candentes cuales fueron la alianza con los republicanos, la integración en la III Internacional y el voto femenino, tres cuestiones ampliamente tratadas por el Comité, las Juntas Generales y las Asambleas. Las decisiones adoptadas no coincidieron siempre con las posturas mayoritarias dentro de la Ejecutiva federal, a pesar de lo cual las mujeres mantuvieron su decisión en una muestra de independencia nunca fácil.

La alianza con los republicanos se cuestionó ya en 1911. Virginia González, a la sazón Presidenta del Grupo, defendió la ruptura con ellos en Junta General por considerarlos un partido burgués, no de clase, y por no portarse siempre bien con el socialismo allá donde habían triunfado. Parte de las asistentes consideraba más importante la alianza de las izquierdas, imprescindible si se quería para derrotar a las derechas. Votadas ambas posturas, la rupturista se impuso por 25 votos contra 7. Cuando en 1919 se vuelva sobre la cuestión en la Asamblea General las posiciones se mantuvieron.

Para entonces el socialismo español se encontraba inmerso en otro debate más sangrante: el de unirse o no a la III Internacional, liderada por los comunistas. El tema ocupó dos años -1919/1921-y tres Congresos. Las Juventudes

39. Para los comicios del 9 de abril de 1916, el acta del Comité celebrado cuatro día antes especifica que «la Comisión balla (sic) en Landó repartiendo hojas de propaganda (suplemento) por todos los colegios electorales y vigilar lo posible».

40. El Socialista, 7-III-1914. Cfra.: Moral VARGaS, Marta del, «El Grupo Femenino Socialista de Madrid..., p. 265. 
Socialistas eran partidarias de retomar la vía revolucionaria como instrumento de cambio social y aceptar los 21 puntos que exigía Moscú para unirse a ellos. La dirección del Partido prefería mantenerse vinculada a la II Internacional. La Agrupación Femenina abordó el tema en varias ocasiones con similar división en su seno. De nuevo Virginia González era partidaria de la ruptura, entendiendo que los rusos no exigían la revolución inmediata, sino estar prestos a iniciarla en el momento oportuno. De nuevo, parte de las asistentes se opusieron. La Agrupación, finalmente, optó por definirse partidaria de la III Internacional siempre que el PSOE conservarse la libertad de acción que tenía. Cuando el partido decidió mantenerse donde estaba, Virginia abandonó la Agrupación y el socialismo.

El voto femenino ${ }^{41}$, por su parte, fue el tema más tratado a lo largo de la vida de la Agrupación Femenina madrileña, agitado por acontecimientos nacionales, internacionales o de ambos tipos a un tiempo. La primera vez corresponde al 8 de noviembre de 1906. El Heraldo de Madrid había empezado a publicar los resultados de una encuesta entre sus lectores sobre si las mujeres debían o no tener derecho de voto, si éste debía o no ser universal, y si debían o no ser elegibles. Al grupo femenino se le pidió su opinión y el Comité debatió al respecto. El que las asistentes estimaran carecer de criterio formado, no evita que se dividieran las opiniones. Carmen Jordán se opuso al voto femenino, mientras el resto consideró que las españolas deberían tenerlo pero no se encontraban preparadas para ello. Dos meses más tarde, acordaron pedir a un compañero una conferencia sobre la conveniencia de que la mujer influyera en el marido a la hora de acercarse a las urnas.

El tema reaparece en 1919 con similar polémica pero en un marco internacional bien distinto. En esos momentos, el reconocimiento de los derechos electorales femeninos se ha convertido en Europa en signo externo de democracia. Inglaterra, aunque restringido, acababa de reconocerlo; Estados Unidos votaba la XIX Enmienda a la Constitución otorgándolo; Rusia, Alemania y otras naciones también lo tenían. Ante esta fiebre sufragista, el proyecto de ley electoral que preparaba el Ministro de la Gobernación, Burgos y Mazo, contemplaba capacitar a las españolas para elegir, no para ser elegidas, y que votasen en días distintos de los varones. Antes de llevarlo al Parlamento buscó otras opiniones, entre las que estuvo la de la Agrupación Femenina Socialista madrileña, que ya se ocupaba de la cuestión. En la Asamblea del

41. Para un estudio de conjunto sobre el tema, véase: CAPEL MARTínez, Rosa $\mathrm{M}^{a}$, El sufragio femenino en la $2^{a}$ República española, Granada, 1975, y Madrid, 1992 y FAGOAGA, Concha, La voz y el voto de las mujeres. El sufragismo en España, 1877-1931, Barcelona, 1985. 
12 de octubre, dedicada casi monográficamente al tema, se reprodujeron las posturas de tres lustros antes y las que encontraremos una década después. Para Ana Posadas el voto femenino era peligroso porque la española no se encontraba educada para su ejercicio. Para Carmen de Burgos, no había que tener miedo a la participación electoral de aquélla, sino trabajar para educarla y que apoyara al socialismo. Además, propuso formar una Comisión al efecto, que integrarían ella misma, Virginia González y una tercera compañera por designar. El proyecto del Ministro, presentado a las Cortes poco después, no llegó a debatirse y el tema desapareció de las preocupaciones políticas ante la delicada situación del país, que desembocaría en la Dictadura del general Primo de Rivera en 1923.

Curiosamente, será éste quien reconozca los derechos electorales a las viudas y solteras para los comicios Municipales en 1924, decretando su inclusión en el Censo Electoral ${ }^{42}$. Tal decisión, insatisfactoria para las feministas y para muchos socialistas por excluir a las casadas, creaba una nueva situación para el hipotético caso de unas elecciones. Consciente de ello, Saborit llama a organizar a las mujeres y a realizar «un debate especial consagrado a la propaganda de nuestras ideas», a fin de que abandonasen «las viejas prácticas religiosas» por «una religión nueva, la del Amor y la Paz». De este modo, si el voto femenino se había implantado para fortalecer a las derechas, «el enemigo, una vez más, nos habrá dado la ocasión para ganarle una fortaleza ${ }^{43}$. La Agrupación Femenina, que además había conseguido el voto corporativo, inició una intensa campaña pro-sufragio. Los donativos recibidos sirvieron para realizar actos en la Casa del Pueblo con la intervención, entre otras, de Victoria Kent, Clara Campoamor y Matilde Huici. También se trasladaron a «los barrios extremos» para acercarse a quienes no habían tenido fácil acudir. Las organizadoras se vanagloriaban de que el gobierno sólo les hubiera suspendido un acto hasta enero de 1925. También se acordó, a propuesta de María Cambrils, elaborar una «Página Femenina», si bien la Federación Nacional de las Juventudes Socialistas puso como condiciones para publicarla el que se adquirieran 100 ejemplares de El Socialista y que se mandasen los artículos corregidos, tarea para la cual se designó un Comité de Redacción integrado por Paca Vega y Carmen González. La campaña pro-voto se mantuvo hasta inicios de 1926, cuando la Agrupación Socialista les pide que detengan su actividad por no haber perspectivas electorales, algo que pone de relieve el

42. Estatuto Municipal y Real Decreto publicados en la Gaceta de Madrid el 9 de Marzo y 12 de Abril de 1924, respectivamente. Cfra.: CAPEL MARTínEZ, Rosa Ma: El sufragio femenino...

43. CAmbrils, María: Feminismo socialista..., pp. 20-21. 
sentido utilitarista desde el que muchos socialistas abordaban aún el tema de los derechos políticos femeninos.

Este apoyo decidido a la causa sufragista puede considerarse una influencia del feminismo socialista que se iba conformando y que empezaba a confeccionar una agenda propia más amplia que la de los primeros tiempos. Si se miran las propuestas que el Comité de la Agrupación Femenina presenta al Congreso del Partido en 1911, vemos que se concretan en cuatro: a) no admitir mujeres en las Agrupaciones donde haya Grupos Femeninos; b) dedicar más importancia al movimiento feminista de clase en la prensa socialista; c) llevar a la práctica las leyes existentes a favor de las mujeres y niños, procurando la prohibición del trabajo nocturno; d) laborar en las agrupaciones por la organización económica y política de los obreros ${ }^{44}$.

Para 1926, las proposiciones del grupo al Pleno de las Juventudes Socialistas incluyen, junto al sempiterno apoyo a los Grupos Femeninos, un extenso programa de reivindicaciones defendido por Claudina García. Las hay de tipo penal: desaparición del $\mathrm{Art}^{\circ} 438$ del Código que absuelve a los maridos que matan a la mujer infiel y posibilidad de que la mujer casada abandone el domicilio conyugal sin poder ser obligada por su marido a volver. Otras afectan al Código Civil: que la mujer pueda disponer y administrar libremente su hacienda; que la madre tenga igual derecho que el padre sobre los hijos, y reconocer los mismos derechos a los hijos ilegítimos que a los legítimos. Entre las políticas estaba ampliar el voto municipal a las mujeres casadas y otorgarlo también para las elecciones de diputados provinciales y a Cortes. Finalmente, se piden reformas tan importantes como que el Estado asuma el deber de sostener a las madres solteras mientras crían a los hijos proveyéndolas de trabajos adecuados o medios económicos suficientes, y que se constituya un cuerpo de personal femenino competente para cuidar a los hijos de las obreras en parques y jardines durante el horario laboral.

Si la importancia social que el tema de la emancipación de la mujer adquiere en la España de comienzos del siglo XX obligó al PSOE a poner más énfasis en los problemas que afectaban a este sexo, la creciente concienciación de las mujeres socialistas constituyó una presión sobre la agenda del partido. Presión que se dejará ver más a la hora de elaborar estrategias políticas que de propiciar la presencia femenina en los órganos de dirección. Así, el programa socialista salido del XI Congreso Nacional (1918) incluía las ya tradicionales reivindicaciones relativas al trabajo femenino y otras más recientes: sufragio,

44. Junta General de 11 de Junio de 1911. Cfra.: Libro de Actas de las Juntas Generales. Marzo, 1906-Febrero, 1915. Archivo y Biblioteca de la Fundación Pablo Iglesias. 
igualdad civil, abolición del trabajo a domicilio y creación de Casas de Maternidad municipales para hijos de obreras. En 1929, el III Congreso Nacional de la Federación de Juventudes Socialistas de España aprueba once reivindicaciones para la mujer, que incluyen las propuestas de la Agrupación Femenina Socialista de 1926, mencionadas anteriormente, más una ley de divorcio y el castigo del delito de seducción seguido de abandono ${ }^{45}$.

La llegada de la II República, el 14 de abril de 1931, daría la oportunidad de ver la dimensión del compromiso socialista con estas reivindicaciones. Una parte las encontramos recogidas ya en la Constitución aprobada ese otoño (Artículos 2, 25, 36, 40, 43, 46). En 1932 salió adelante la primera ley de divorcio, tras ardoroso debate en Cortes y crispada polémica en la sociedad. También se creó un Seguro de Maternidad para las trabajadoras, siguiendo, en parte, los términos del nacido en 1929. En 1935 se abolió la prostitución. Sin embargo, nada se hizo para terminar con la discriminación salarial, presente en las Bases de Trabajo aprobadas durante el período. El tema tenía demasiados opositores. Tampoco era fácil, ni hubo tiempo, para adecuar los Códigos Civil y Penal al mandato constitucional de igualdad.

\section{El techo de cristal}

La apertura de la agenda del PSOE a las reivindicaciones de las mujeres no se correspondió con una mayor incorporación a las labores de responsabilidad ni en el partido ni en las Juventudes. Entre los delegados a los Congresos, la presencia femenina es meramente testimonial en el mejor de los casos: una, dos, a lo sumo tres. Lo frecuente es que se reduzca a la o las representantes que correspondían a la Agrupación Femenina Socialista de Madrid. Doce fueron las delegadas asistentes a las reuniones congresuales del PSOE entre 1912 y 1932. La primera fue Virgina González, y la única que repitió tres veces más (1915, 1919 y 1921); María Hernández acudió a dos (1920, 1921), mientras las restantes sólo a una. Por el grupo femenino madrileño lo hicieron Virginia y María, Clementa Calvo (1918), Claudina García (1921), Carmen González (1919) y María Merino (1918). Representando a Agrupaciones Socialistas fueron: Nieves Camacho por Puertollano (1927), Regina García por Murcia (1931), Luz García por Madrid (1928), Manuela Sánchez por San Lorenzo de El Escorial (1932) y Francisca Vega por Toledo y Carpio del Tajo (1918). Además, Margarita Nelken sería Vicepresidenta del congreso de 1932, sin duda en reconocimiento a su personalidad.

45. Para un análisis más detallado de estos aspectos y los siguientes, véase: CAPEL MARTíNEZ, Rosa $\mathrm{M}^{\mathrm{a}}$, Socialismo e igualdad... 
De la Ejecutiva del PSOE sólo formó parte Virginia González, elegida Vocal en 1915, pasando a ocupar el recién creado puesto de Secretaria Femenina en el siguiente Congreso de 1918. De momento faltan datos sobre las tareas que se le asignaron y, en cualquier caso, puesto y titular desaparecieron tras los Congresos Extraordinarios de 1919-1921.

Habrá de pasar un lustro para que se vuelva a hablar de una Secretaría Femenina. Ocurre durante la Junta General Ordinaria de la Agrupación Femenina Socialista de Madrid en 1926 y se propone que integre a todas las Sociedades de Mujeres. Como la Agrupación se disolvió al año siguiente, la iniciativa no tuvo recorrido. Mas la idea no debió desaparecer, porque durante la Guerra Civil se creó un Secretariado Femenino dentro del PSOE.

Desde el inicio de la contienda habían sido muchas las socialistas alistadas en la «Agrupación de Mujeres Antifascistas» y «LUnió de Dones de Catalunya», controladas por las comunistas, para hacer un frente común. Sin embargo, la convivencia no era fácil, al menos entre dirigentes. El testimonio de Matilde Cantos, representante en el "Comité Nacional de Mujeres contra la Guerra y el Fascismo», no deja duda al respecto. A su paso por Madrid en 1937 informaba de los malos ratos que pasaba y de lo inútil de sus esfuerzos por imponer la línea socialista en la asociación. Sólo si las compañeras se afiliaban masivamente podría reconducirse la situación ${ }^{46}$.

La empresa no podía ser más difícil, sobre todo teniendo en cuenta la creciente fuerza política del Partido Comunista. Quizás por ello, Ramón Lamoneda expresaba la preocupación que sentían los socialistas por el movimiento femenino ante el Congreso Nacional del PSOE de ese año. Lamentaba que hubiera sido uno de los temas importantes no tratados por falta de tiempo y anunciaba que la Ejecutiva había encargado a Matilde de la Torre un proyecto y decidido formar un Secretariado Femenino, estándose pendiente de hallar un local para ponerlo en marcha. No existe apenas información sobre cuándo se constituyó ni acerca de su funcionamiento, salvo que a finales de 1938 su Comisión Directora contaba con Matilde Cantos, Claudina García y Julia Álvarez Resano, quien actuaba de Secretaria ${ }^{47}$. Las oficinas se abrían todas las tardes de 5,00 a 7,00 hs. en los locales del Partido para atender a cuantas mujeres quisieran colaborar. Los viernes a las 5,00 h. se reunía la Comisión, que había solicitado información sobre los Grupos Femeninos y Secretarías

46. Acta de la reunión celebrada por el Comité del Grupo Femenino Socialista y responsables de Círculos Sociales. 27 de abril de 1937. Archivo y Biblioteca de la Fundación Pablo Iglesias.

47. Correspondencia de Ramón Lamoneda con el Secretariado Femenino. 1938. Archivo y Biblioteca de la Fundación Pablo Iglesias. 
existentes, con indicación de la fecha de fundación y el número de afiliadas. Asimismo, había acordado buscar la solidaridad de Organizaciones Femeninas de otros partidos políticos nacionales y de Organizaciones Socialistas en el extranjero ${ }^{48}$.

La derrota republicana en 1939 significó la desaparición de este órgano y la desarticulación de los Grupos Femeninos dentro del PSOE. Habrían de pasar más de dos décadas antes de que volviera a reorganizarse algo similar y cuarenta años para tener un órgano estable dentro de la Ejecutiva Federal que se ocupase de los problemas de las mujeres e impulsase políticas de igualdad dentro y fuera del partido ${ }^{49}$.

48. Carta de la Comisión Directora del Secretariado Femenino de 24-XII-1938 dirigida a la Comisión Ejecutiva del PSOE. Cfr.: Correspondencia de Ramón Almoneda con el Secretariado Femenino. 1938. Archivo y Biblioteca de la Fundación Pablo Iglesias.

49. Cfr.: CAPel Martínez, Rosa $\mathrm{M}^{\mathrm{a}}$, Socialismo e igualdad... 